\title{
We are in the Same Boat: Group Therapy as a Treatment for Psychological Distress in Dating Violence Survivors
}

\author{
Pradipta Christy Pratiwi \\ Universitas Negeri Semarang \\ pradiptacp@mail.unnes.ac.id \\ Tri Esti Budiningsih \\ Universitas Negeri Semarang \\ triesti@mail.unnes.ac.id
}

\author{
Fatma Kusuma Mahanani \\ Universitas Negeri Semarang \\ fatma.psi@mail.unnes.ac.id \\ Julian Adrian Halim \\ Universitas Katolik Atma Jaya \\ julian.adrian.halim@gmail.com
}

\begin{abstract}
Young adults are synonymous with the task of developing intimacy. This phase is inseparable from the problem of dating violence. This situation is a social stressor that causes a negative stress response commonly known as psychological distress. The purpose of this study is to provide treatment for 5 young adults who have experienced dating violence with online group intervention. The intervention design was carried out for seven 60-90 minutes sessions. The evaluation was done using observation, DASS, and BDI-II. Friedman's test showed a significant result for depression (BDI-II, $\chi^{2}{ }_{F}=6.533, p=.038 ;$ DASS, $\chi^{2}=6.533, p=.038$ ) and anxiety $\left(\chi_{F}^{2}=6.000, P=.050\right)$, and a non-significant result for stress $\left(\chi_{F}^{2}=3.500, p=.174\right)$.
\end{abstract}

Keywords: Dating violence; group therapy; psychological distress; cognitive behavioral therapy

Received I4 October 202I/Accepted 25 February 2022 @Author all rights reserved

\section{Introduction}

Young adult age range is a time for individuals to experiment on roles and responsibilities toward adulthood. Erikson's developmental psychology model states that young adults face a crisis of intimacy versus isolation. If a person succeeds through this phase and forms a personal commitment with the opposite sex, she will also better understand herself and understand the characteristics of the partner that suits her (Papalia \& Martorell, 2014). Intimate relationships require sacrifice and compromise. Young adults are tasked to solve problems and develop an ethical sense in relationships. James (2008) 
stated that $20 \%$ of men around the age of $18-25$ years and $17 \%$ of men aged $26-35$ years commit violence against their partners.

Dating violence has become a theme for concern in global research. Dating violence (American Psychological Association, in Grace et al., 2018) is defined as violence that is exposed to the victim which can have a negative impact on the victim both in the short and long term. A systematic review study conducted by Taquette and Monteiro (2019) analyzed 35 research papers of which $71.4 \%$ were conducted in the United States. Their review found that the prevalence of dating violence in both males and females amounts to more than 50\%. Viejo et al. (20I6) cross-sectional study in Spain and the UK showed that approximately $23 \%$ of young adults reported themselves as survivors of dating violence. Thirty percent of them also physically abuse their partner. In both countries, most of the violence in dating is physical. A study of 23 young adult women who had experienced violence from their parents in childhood and adolescence, showed that they were in a relationship with an abusive partner during high school (Haselschwerdt et al., 202I). With a high prevalence, these findings reveal that intimate partner violence is unfortunately a common occurrence.

From the number of cases that have occurred, violence in dating has an impact on psychological problems on the survivors. Dating violence may cause psychological problems such as high levels of depression, suicidal thoughts, and problems with alcohol use and their educational problems (Banyard \& Cross, 2008). However, it was reported that women experience more severe consequences than men. Through an interview with 218 women who experienced interpersonal violence, Adams et al. (202I) found that these women experienced posttraumatic stress disorder (PTSD) at a severe level and showed symptoms of depression. Both PTSD and depression are indications of psychological distress. A further study reported that the of dating violence include low physical health, psychological distress, mental illness, and the tendency of using addictive substances (Carbone-Lopez et al., 2006).

In Indonesia, Pratiwi and Yasa (2021) obtained data from 258 women who experienced dating violence. The types of violence they experienced varied from physical, psychological, and sexual violence, and some even experienced more than one type of dating violence simultaneously. Research showed that women who experience dating violence have a higher psychological distress score than 
women who do not experience it (Pratiwi \& Yasa, 202I). These previous studies indicate that women who have experienced intimate partner violence experience low psychological well-being.

Based on the consequences of dating violence on young women, a curative intervention is important. The treatment is usually carried out on victims or survivors of dating violence in the form of counseling or therapy with various approaches such as cognitive behavioral therapy (CBT). A CBTbased treatment is focused on problem solving and simultaneously helps clients to manage their emotions and thoughts (Pratiwi, 2017). Furthermore, CBT focuses on helping clients overcome their negative automatic thoughts which may be irrational at times and transform it into a more logical and realistic thought process. Indeed, CBT-based treatments' objective is to target clients' less adaptive thoughts, beliefs, and subjective interpretations on conditions and situations and implant the knowledge, skills, and coping strategies to independently deal with similar situations in the future (Luzanil \& Menaldi, in press).

CBT-based treatments can also be administered in individual and/or group programs (Sullivan et al., 2013; Howard et al., in Pratiwi, 2017). Group therapy has some advantages over individual therapy as it provides clients with the opportunity for vicarious learning, learning to understand similar problems through other people's point of view, and also the room for problem solving and finding constructive solutions to interpersonal problems (Gidron, 20I3). Furthermore, group therapy also helps clients to increase their social functioning through interaction with others who face similar problems so that they are able to implement new coping strategies more effectively to their own situations (Ezhumalai et al., 2018). A group intervention has the advantage of enabling clients to interact with other people who face similar situations (Forsyth, 2019).

The following described studies have reported the effectiveness of CBT-based programs for treating domestic violence patients. Johnson et al. (20II) applied a CBT-based treatment (HOPE Program: Helping to Overcome PTSD through Empowerment) to treat a group of intimate partner violence survivors. The program consisted of 12 meetings with each lasting for 60-90 minutes and an additional individual intervention approach. The authors reported that the program effectively treated several symptoms of emotional numbing and depression among others. Kim and Kim (200I) research found that a group intervention significantly decreased anxiety in intimate partner violence survivors. 


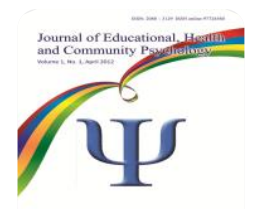

Despite the evidence for group-based treatment in treating IPV patients, a study conducted within the Indonesian setting remains to be seen.

\section{The Present Study}

Women are more susceptible to violence than men due to the nature of the patriarchal culture in Indonesia. This is related to the issue of gender inequality which considers women as weak individuals and has a lower status than men (Poerwandari, in Grace et al., 2018). Furthermore, previous study in Indonesia found that women who are survivors of dating violence reported a high psychological distress (Pratiwi \& Yasa, 202I). Therefore, we designed the research and intervention specifically with young women participants in mind.

This study will use a group intervention approach. Group intervention facilitates individuals for interpersonal learning, individuals who experience distress can feel acceptance from group members and at the same time practice being a person full of empathy for other group members. Therefore, group intervention provides a therapeutic factor that helps group members to be more prosperous and develop hope after experiencing an unpleasant experience (Brabender et al., 2004).

The present study provides novelty and uniqueness in the form of a self-made cognitive behavioral therapy-based group counselling protocol titled as "MF (Moving Forward): online group intervention for survivors of dating violence". Drawing from the CBT theory, we designed a CBT intervention aimed to: (I) facilitate the dating violence survivors to change maladaptive thoughts, feeling, and behavior to be more realistic; (2) provide social-support and learn from the others in group; and (3) analyze the effect of dating violence on their psychological aspect, like stress, anxiety and depression.

In summary, I) previous research suggests that the impact of dating violence on women may be severe (Banyard \& Cross, 2008; Carbone-Lopez et al., 2006; Taquette \& Monteiro, 2019), 2) previous research in Indonesia suggests that dating violence increases the psychological distress in women (Pratiwi \& Yasa, 2021), and 3) previous research found that cognitive behavior therapy-based counselling can be used for treatment of psychological distress in dating violence survivors. Therefore, 


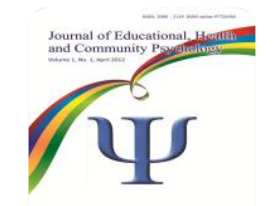

this study's objective is to study the effectiveness of cognitive behavior therapy-based group counselling can decrease psychological distress in dating violence survivors.

\section{Method}

Participants

The population of this research is individuals aged in the range of young adults who have experienced dating violence. Dating violence can be in the form of physical violence, sexual violence, or psychological violence. The sample of this study was young adults with the following characteristics:

\section{Women aged $18-30$ years}

2. Have experienced dating violence

3. Willing to attend intervention sessions for seven meetings according to the agreed informed consent.

We asked the participants for their informed consent before data intake. The informed consent included information on confidentiality of data both during the intervention process and the use of data in research, the risks of participation, and the rights of participations. With the approval of participants, referral information was given to participants who needed additional intervention.

\section{Design}

The research design used a quasi-experimental one-group pretest-posttest design. This design uses one small group of samples who are given an intervention without a comparison group, accompanied by measurements at least once before the intervention (pretest) and once after the intervention (posttest) (Gravetter \& Forzano, 20I I). This type of design uses a small sample size, making it suitable for use in clinical research (Kerlinger \& Lee, 2000). Participants receive a six-session online CBTbased group intervention with pretest conducted in the first session and posttest in the last session. The present research also included a follow up session I month after the last session. The approach used in this research is quantitative (questionnaire) and qualitative (observations and interviews). Therefore, the effectiveness of group intervention was evaluated from the difference in scores between pretest and posttest and qualitatively. 


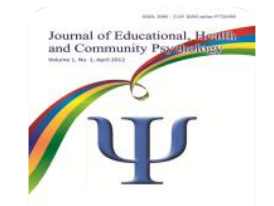

\section{Procedure}

This research consists of preparation, implementation, and follow up phases. During the preparation phase, we conducted an expert judgement for the protocol we have designed. This protocol was reviewed by 2 psychologists who are experts in the field of clinical psychology and have experience in individual and group psychological interventions. The protocol was adjusted according to the review and feedback given by expert judgement. Revision includes the material arrangement between depression, anxiety, and stress, changed to stress, anxiety, and depression. Further revision was made by focusing the second session on processing past experiences related to dating violence and psychoeducation of participants about healthy relationships.

Participants were recruited through an online flyer which was published for 5 days. Prospective participants filled out a google form containing 3 questionnaires, namely personal data, BDI questionnaire, and DASS questionnaire. Samples with the highest psychological distress were invited to an informed consent meeting and subsequent intervention.

The implementation phase refers to applying the CBT-based group intervention on selected participants. The intervention lasted for 6 sessions with a time duration of around $60-90$ minutes each session. Pretest data was collected at the first session and posttest at the last session. A follow up session was conducted I month after the last session. Data intake for the pretest, posttest, and follow up session used the BDI and DASS.

\section{Intervention}

Interventions conducted in this study comprise of 7 sessions. Based on the consequences that are often experienced by survivors of dating violence and the treatments carried out on survivors of dating violence, we designed a group intervention protocol based on Aaron Beck's cognitive behavior therapy theory. This protocol focuses on changing the irrational thoughts, feelings and behaviors of the participants. On the other hand, this intervention also provides microsystem learning for participants in the form of group intervention based on Yalom's group therapy theory. Expert judgement process was conducted by two experienced clinical psychologists. This protocol has also obtained a copyright certificate (IPR) from the government. 


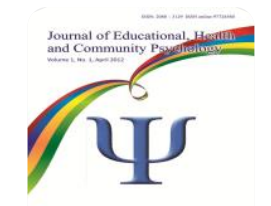

\section{Instrument}

The DASS is used to measure depression, anxiety, and stress, as symptoms of individual emotional management failure. DASS has been used in various cultural backgrounds, such as Asian, Hispanic, American, British, and Australian (Oei et al., 20I3). The Depression Anxiety Stress Scale (DASS) measurement developed by Lovibond, was adapted to the Indonesian version and has been tested on I45 I adults (Widyana et al., 2020). The adaptation process resulted in a satisfactory psychometric characteristic. The reliability coefficient of the depression scale is .954 , the anxiety scale is .903 , and the stress scale is 917 . The results of the confirmatory factor model also show good accuracy with the hypothetical model. Beck Depression Inventory (BDI-II) measuring instrument with a reliability of .9 for the Indonesian version (Ginting et al., 20I3).

\section{Data Analysis}

Data was analyzed using descriptive statistics and inferential statistics. Descriptive statistics was used to explore and compare depression, anxiety, and stress levels of participants across pre, post, and follow-up tests. Inferential statistics was used for significance testing. Statistical analysis was conducted using Friedman's ANOVA for repeated measures. Subsequent post hoc analysis was conducted using Conover's post hoc comparison test with Bonferroni correction. Effect size was calculated using Kendall's W. Furthermore, this study also used a qualitative approach and explored the dynamics and changes of participants before and after intervention. Qualitative data were acquired through observation of responses during intervention and pre-, and post-intervention evaluation interviews. The differences of scores from pre, post, and follow-up tests and statements of participants provided the effect of the intervention. 


\section{,}

Tabel I.

CBT-Based Group Intervention Plan

\begin{tabular}{|c|c|c|c|}
\hline Session & Time Duration & Activities & Objectives \\
\hline $\mathrm{I}$ & 60 minutes & $\begin{array}{l}\text { - } \text { Pretest } \\
\text { - Psychoeducation and } \\
\text { sharing about dating } \\
\text { violence } \\
\text { - Progressive relaxation } \\
\text { - Debriefing }\end{array}$ & $\begin{array}{l}\text { introduction and explore the participants } \\
\text { experience about dating violence }\end{array}$ \\
\hline 2 & 90 minutes & $\begin{array}{l}\text { - Psychoeducation and } \\
\text { sharing about psychological } \\
\text { distress as effects of dating } \\
\text { violence } \\
\text { - ABC's model (irrational } \\
\text { thoughts identification) and } \\
\text { dispute } \\
\text { - Progressive relaxation } \\
\text { - Debriefing }\end{array}$ & $\begin{array}{l}\text { participants can identify and dispute } \\
\text { irrational beliefs related to dating violence } \\
\text { experiences so they can have better } \\
\text { consequences (behavior / emotion); } \\
\text { participants share about their own } \\
\text { experience and give support for the } \\
\text { others. }\end{array}$ \\
\hline 3 & 90 minutes & $\begin{array}{l}\text { - Psychoeducation and } \\
\text { sharing about coping stress } \\
\text { - ABC's model (irrational } \\
\text { thoughts identification) and } \\
\text { dispute } \\
\text { - Breathing relaxation } \\
\text { technique } \\
\text { - Butterfly hugs technique }\end{array}$ & $\begin{array}{l}\text { participants analyse the stress symptoms } \\
\text { experienced; participants learn and } \\
\text { exercise coping stress. }\end{array}$ \\
\hline 4 & 90 minutes & $\begin{array}{l}\text { - Psychoeducation and } \\
\text { sharing about anxiety } \\
\text { - ABC's model (irrational } \\
\text { thoughts identification) and } \\
\text { dispute } \\
\text { - Breathing relaxation } \\
\text { technique } \\
\text { - Safe place and I-message } \\
\text { technique }\end{array}$ & $\begin{array}{l}\text { participants analyse the anxiety symptoms } \\
\text { experienced; participants learn and } \\
\text { exercise anxiety-reducing technique. }\end{array}$ \\
\hline 5 & 90 minutes & $\begin{array}{l}\text { - Psychoeducation and } \\
\text { sharing about depression } \\
\text { - ABC's model (irrational } \\
\text { thoughts identification) and } \\
\text { dispute } \\
\text { - Evidence hunting about their } \\
\text { beliefs from significant } \\
\text { others } \\
\text { - Schedule activity }\end{array}$ & $\begin{array}{l}\text { participants analyse the depression } \\
\text { symptoms experienced; participants learn } \\
\text { and exercise depression-reducing } \\
\text { techniques. }\end{array}$ \\
\hline 6 & 60 minutes & $\begin{array}{l}\text { - Evaluation for all session } \\
\text { - DASS \& BDI-II } \\
\text { measurement }\end{array}$ & $\begin{array}{l}\text { participants reflect on the all session } \\
\text { activities; the termination of intervention }\end{array}$ \\
\hline 7 & 60 minutes & $\begin{array}{l}\text { - the follow-up session } \\
\text { - DASS \& BDI-II } \\
\text { measurement }\end{array}$ & $\begin{array}{l}\text { getting information about daily activities of } \\
\text { participants after the intervention (efficacy } \\
\text { of the treatment). }\end{array}$ \\
\hline
\end{tabular}




\section{F}

\section{Results}

\section{Participant Characteristics}

A total of 59 candidates were initially recruited. The candidates filled in a screening test via Gform. After the disqualification and filtering process, 7 candidates were retained. We contacted the candidates to receive their informed consent, and a final total of 7 participants consented for intervention. Participants who were not chosen for the intervention received dating violence psychoeducation via email. Table 2 provides a summary of participants included in the intervention. Participant 4 and 7 dropped out of the intervention program and thus will not be included in further analysis. We offered them additional private intervention sessions.

Table 2

Participant Characteristics

\begin{tabular}{|c|c|c|c|c|c|c|c|c|}
\hline \multirow{2}{*}{\multicolumn{2}{|c|}{ Characteristics }} & \multicolumn{7}{|c|}{ Participant } \\
\hline & & $\mathrm{I}$ & 2 & 3 & $4^{*}$ & 5 & 6 & $7 *$ \\
\hline Age & & 23 & 24 & 21 & 19 & 18 & 22 & 27 \\
\hline \multicolumn{2}{|c|}{ Type of dating violence } & $\begin{array}{l}\text { physical, } \\
\text { psychologi } \\
\text { cal, and } \\
\text { sexual } \\
\text { violence }\end{array}$ & $\begin{array}{l}\text { psychologi } \\
\text { cal, } \\
\text { economic } \\
\text { al, and } \\
\text { activity } \\
\text { restriction } \\
\text { s }\end{array}$ & $\begin{array}{l}\text { psycholo } \\
\text { gical } \\
\text { violence } \\
\text { and } \\
\text { activity } \\
\text { restrictio } \\
\text { ns }\end{array}$ & $\begin{array}{l}\text { psycholo } \\
\text { gical, } \\
\text { sexual, } \\
\text { and } \\
\text { activity } \\
\text { restrictio } \\
\text { ns }\end{array}$ & $\begin{array}{l}\text { physical, } \\
\text { sexual, } \\
\text { and } \\
\text { activity } \\
\text { restrictio } \\
\text { n }\end{array}$ & $\begin{array}{l}\text { psycholo } \\
\text { gical } \\
\text { violence } \\
\text { and } \\
\text { activity } \\
\text { restrictio } \\
\text { ns }\end{array}$ & $\begin{array}{l}\text { psycholo } \\
\text { gical, } \\
\text { sexual } \\
\text { and } \\
\text { activity } \\
\text { restrictio } \\
\text { n }\end{array}$ \\
\hline \multirow[t]{2}{*}{ BDI } & Depression & 51 & 37 & 32 & 34 & 37 & 38 & 31 \\
\hline & Depression & $4 I$ & 39 & 39 & 49 & 47 & 39 & 42 \\
\hline \multirow[t]{2}{*}{ DASS } & Anxiety & 36 & 28 & 31 & 34 & 38 & 27 & 31 \\
\hline & Stress & 36 & 39 & 34 & 33 & $4 I$ & 36 & 25 \\
\hline
\end{tabular}

Note: $*$ dropped out during the intervention sessions

Comparison of depression levels among participants across pre, post, and follow-up test

Figure I displays the changes of scores in depression of participants based on pre, post, and followup tests. The depression was measured by DASS. Meanwhile, figure 2 displays the changes of scores in depression of participants as measured by BDI-II. 


\section{座}

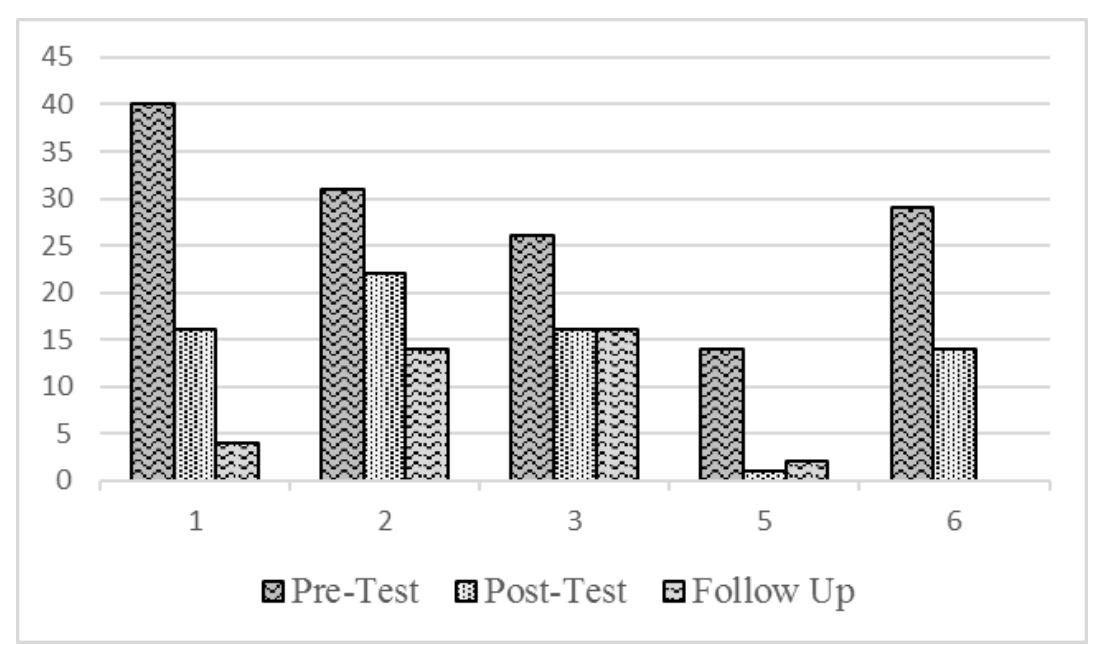

Figure I. Comparison of depression levels (DASS) of participants

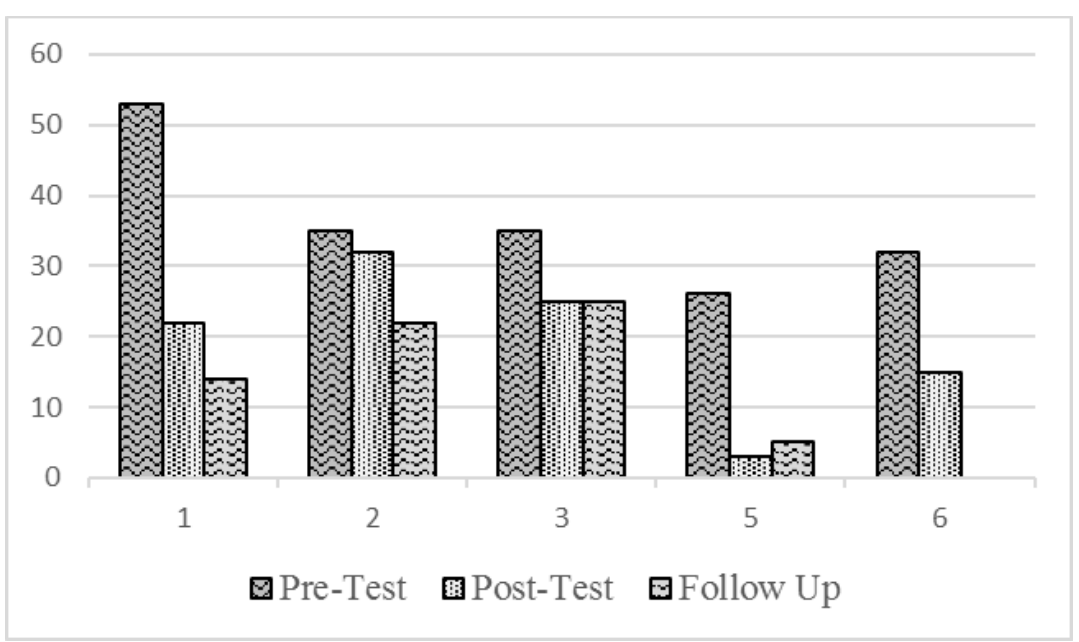

Figure 2. Comparison of depression levels (BDI-II) of participants

Both figures indicate that the group therapy intervention based on CBT decreased the levels of depression in participants. All participants showed a lower level of depression as measured in posttest and follow up. It is worth noting that the depression scores from DASS and BDI-II are almost identical, and the graph showed a similar trend.

Comparison of anxiety levels among participants across pre, post, and follow-up test

Figure 3 shows the changes of anxiety levels among participants based on DASS measured at pre, post, and follow-up tests. Based on the graphs, it can be observed that the anxiety levels decrease as 


\section{F}

measured. Curiously, participant 2's anxiety level from pre to posttest did not decrease by that much, however the follow up test showed a much smaller score of anxiety.

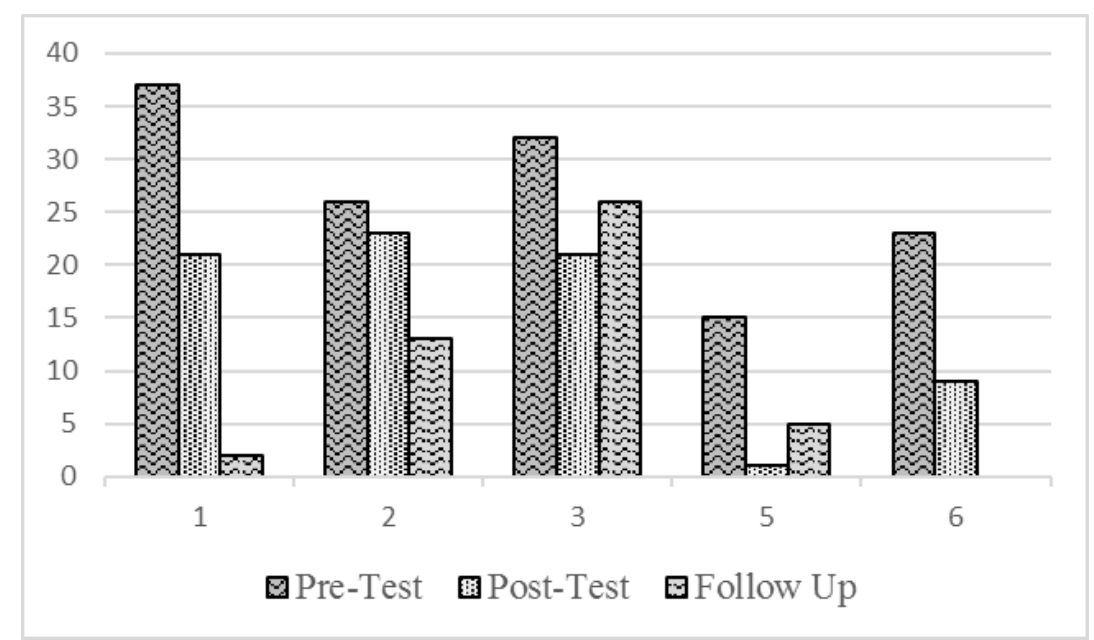

Figure 3. Comparison of anxiety levels (DASS) of participants

Comparison of stress levels among participants across pre, post, and follow-up test

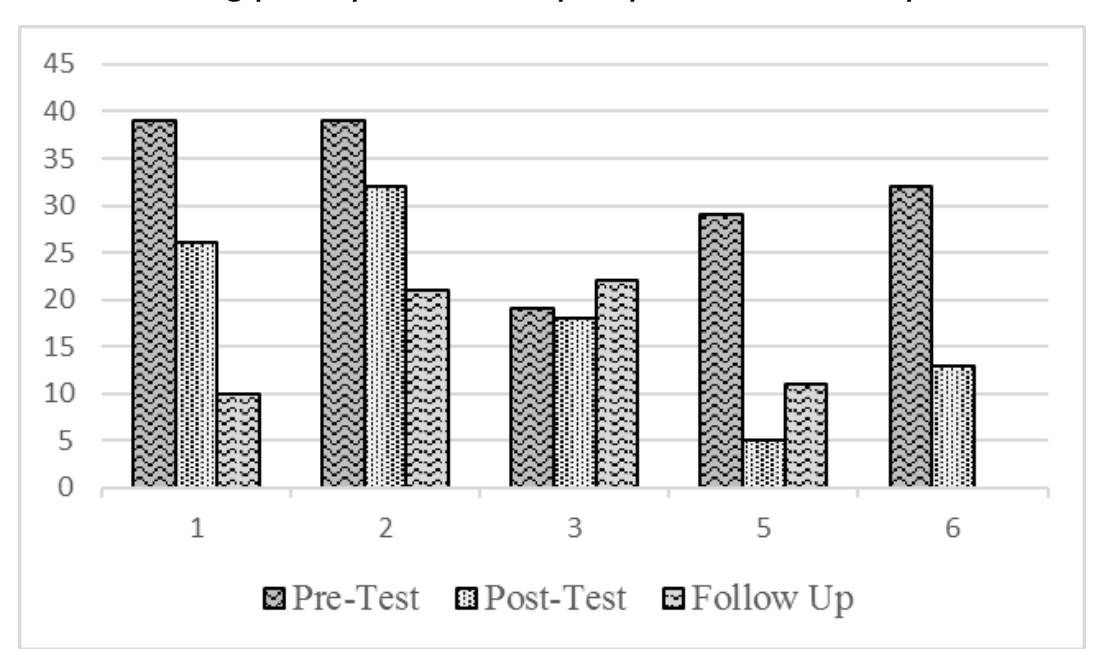

Figure 4. Comparison of stress levels (DASS) of participants

Figure 4 presents the changes of stress level from pre, post, to follow-up tests. The graph indicates that participants' stress level decreased after the intervention. 


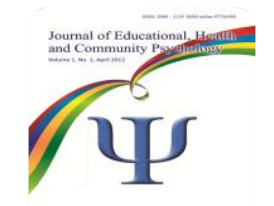

\section{Hypothesis Testing}

In the previous sub-chapters, we have presented the results of participant I, 2, 3, 5, and 6. Participant 6 did not complete the follow up test. Therefore, for the hypothesis testing we only included 4 participants (participant I, 2, 3, and 5). The following is a table summarising the hypothesis testing with Friedman's ANOVA.

Table 3

Friedman's ANOVA Results \& Effect Size

\begin{tabular}{llllcl}
\hline Variable & Chi-Squared & $p$-value & Kendall's W & $\overline{r_{s}}$ & Verdict \\
\hline Depression (BDI-II) & 6.533 & .038 & .817 & .756 & HO rejected \\
Depresion (DASS) & 6.533 & .038 & .817 & .756 & HO rejected \\
Anxiety (DASS) & 6.000 & .050 & .750 & .667 & HO rejected \\
Stress (DASS) & 3.500 & .174 & .438 & $.25 \mathrm{I}$ & HO retained \\
\hline
\end{tabular}

Friedman's test showed a significant result for depression (BDI-II, $\chi_{F}^{2}=6.533, p=.038$; DASS, $\chi_{F}^{2}=$ 6.533, $p=.038)$ and anxiety $\left(\chi_{F}^{2}=6.000, p=.050\right)$, and a non-significant result for stress $\left(\chi_{F}^{2}=3.500\right.$, $p=.174)$. The result indicates that there is a difference of scores between pre-, post-, and follow up tests for depression (both DASS and BDI-II) and anxiety. Post hoc tests using Conover's multiple comparison were run for depression and anxiety. Curiously, post hoc tests found no significant differences between compared groups of datasets. For a summary, see table $\mathbf{x}$.

Table 4

Conover's Multiple Comparison Post Hoc Test with Bonferroni Correction

\begin{tabular}{|c|c|c|c|c|}
\hline \multicolumn{2}{|c|}{ Comparisons } & T-stat & $p$-value & Verdict \\
\hline \multicolumn{5}{|c|}{ Depression (BDI-II) } \\
\hline \multirow[t]{2}{*}{ Pretest } & Posttest & 2.031 & .266 & Retained \\
\hline & Follow Up & 2.400 & .160 & Retained \\
\hline Posttest & Follow Up & 0.369 & $\mathrm{I}$ & Retained \\
\hline \multicolumn{5}{|c|}{ Depression (DASS) } \\
\hline \multirow[t]{2}{*}{ Pretest } & Posttest & 2.031 & .266 & Retained \\
\hline & Follow Up & 2.400 & .160 & Retained \\
\hline Posttest & Follow Up & 0.369 & $\mathrm{I}$ & Retained \\
\hline \multicolumn{5}{|c|}{ Anxiety (DASS) } \\
\hline \multirow[t]{2}{*}{ Pretest } & Posttest & 2.121 & .234 & Retained \\
\hline & Follow Up & 2.121 & .234 & Retained \\
\hline Post-Test & Follow Up & 0.000 & $\mathrm{I}$ & Retained \\
\hline \multicolumn{5}{|c|}{ Stress (DASS) } \\
\hline \multirow[t]{2}{*}{ Pretest } & Posttest & 1.768 & .383 & Retained \\
\hline & Follow Up & 1.414 & .621 & Retained \\
\hline Posttest & Follow Up & 0.354 & $\mathrm{I}$ & Retained \\
\hline
\end{tabular}


Subsequently Kendall's W was also calculated and converted into the mean Spearman correlation coefficient. According to Field (2005), the formula to convert Kendall's W into mean Spearman correlation coefficient is as follows.

$$
\bar{r}_{s}=\frac{k W-1}{k-1}
$$

Cohen (1992) index of effect sizes stated that a correlation coefficient of .10 indicates small effect, .30 medium effect, and .50 a large effect. Referring to table 4 , it can be concluded that there is a large effect size for depression $\left(\overline{r_{s}}=.756\right)$ and anxiety $\left(\overline{r_{s}}=.667\right)$ and a small to medium effect size for stress $\left(\overline{r_{s}}=.25 \mathrm{I}\right)$. In the case of a large effect, the effect accounts for $25 \%$ of total variance, and the medium effect accounts for $9 \%$ of the total variance (Field et al., 2012).

\section{Qualitative Data Description}

Some important notes from the observations about each participant in this study are as follows.

Participant $I$. The participant assessed herself as a caring person, gentle in her attitude but sometimes also difficult to manage anger. She also often experiences overthinking. During the group intervention, she was quite cooperative in following the series of activities in earnest. The impact of dating violence that she has experienced is that until now, sometimes the verbal abuse she has received in the past still appears in her dreams. It came after she talked about her former dating partner. Symptoms of physical anxiety include cold sweat and frequent crying. Participant I was also able to find insights from events experienced by other participants in the group, for example, she remarked that she has the right to defend herself when someone else commits violence to her. Some of the techniques that she considered suitable were butterfly hugs, breathing relaxation, in addition to cognitive identification which helped her to better control her thoughts so she would not be easily anxious.

Participant 2. She described herself as an individual who do not easily give up on circumstances. She is someone who takes the initiative to ask questions and express her opinions throughout the group intervention session. She tends to withdraw from the environment when she is stressed because she 
feels that other people will not understand her even though she will tell her complaints so that it will only increase the severity of the stress she experiences. She also often experiences panic attacks, shortness of breath, cries, lack of appetite, and refuse to see other people when she is stressed. When problems arise in her dating relationship, she expresses emotions through slamming objects and exercising. The insights she received during the intervention sessions were also related to her dependent characteristics. According to her, this has led to her persistence despite realizing that her former relationship was unhealthy. After attending a series of group intervention sessions, she felt that breathing relaxation is a solution she can use to managing emotions. Techniques for changing distortions of thought also help her become more realistic when feeling stressed out by negative thoughts.

Participant 3. Participant 3 describes herself as a person who is often disturbed by negative thoughts, she also feels like a person who is often engage in overthinking. She often presents herself as strong in front of others, but in fact, she is fragile. She often experiences problems because she tends to hide her feelings, but it can be seen from her behavior that is easily read by other people so that it triggers fights in her former romantic relationships. She sometimes feels the sudden urge to cry, feel depressed, the urge to be alone in her room, and terrified that unpleasant experiences will repeat themselves. Therefore, she tends to choose to remain silent. While performing several skills to combat stress and anxiety, she conveyed that she needed the help of other group members to motivate her so that she could apply the techniques taught to the fullest. The insight that she gets is that even though she has had unpleasant experiences in dating relationships, in the future she wants to be more empathetic and able to compromise with others.

Participant 5. Participant 5 explained that she was an energetic person, full of enthusiasm and even overpowering. The traits she conveyed were felt during the group intervention sessions. Participant 5 tends to be an energizer for other group members. Behind a person who always appears cheerful, she tends to be reluctant to tell other people her own thoughts and feelings. The experience of a violent relationship with her former dating partner made her less able to convey her feelings properly. She also tends to generalize other people; this affects her feelings which tend to be negative. She feels tired because she is often more concerned with other people's feelings than her own feelings. From 


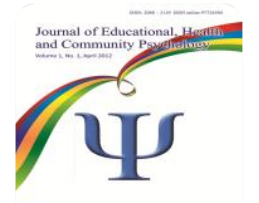

the group intervention process, she gained the insight that she needed to be more courageous in expressing her opinion/feelings to others if it was good for her and did not harm others. She also realized that the treatment of her former dating partner had an impact on the way she treated her partner now. In the past she received possessive treatment from her partner, now she is the one who is possessive towards the partner. She started to change her behavior. As for the techniques that suits her, she prefers breathing relaxation to butterfly hugs and safe places. She also found benefit in controlling her mind with realistic thinking exercises and I-message to help calm down.

Participant 6. Participant 6 described her personality as someone cheerful when with other people but turns melancholy when alone. Sometimes she also likes to be alone. During her first experience of practicing relaxation, she felt dizzy when she closed her eyes even though her feelings got better after relaxation. She is quite familiar with meditation which she self-taught. Furthermore, she tends to run away whenever there is a problem by shutting herself in her room and refusing to talk to anyone. Physical symptoms that appear are usually shortness of breath. Currently, she is afraid to have a relationship with the opposite sex because of her previous experiences of violent dating and was almost raped by her boss while on duty. The impact that is currently being experienced tends to be depressive and has no meaning in life, there is nothing to be achieved in life. In the 5th session of the meeting, she gained the insight that she was not alone with her unpleasant experiences so far, it turned out that many other people had also experienced them. She felt that she received psychological support, felt more comfortable and calmer with herself after sharing experiences and listening to experiences from other group members. 
Table 5

Comparison of Mental Health State of Participants Before and After Intervention

\begin{tabular}{|c|c|c|}
\hline Participant & Before Intervention & After Intervention \\
\hline Participant I & $\begin{array}{l}\text { "Since experiencing violence from my } \\
\text { boyfriend, I like to self-destruct by } \\
\text { drinking alcohol and smoking, I'm also } \\
\text { angry with myself. I think that good } \\
\text { people will not be accepted. His rude talk } \\
\text { keeps appearing in my dreams. I also } \\
\text { often cry because of anxiety." }\end{array}$ & $\begin{array}{l}\text { "I can control myself more. I } \\
\text { thought I could love myself more. } \\
\text { My smoking behavior, drinking } \\
\text { alcohol, and nightmares reduced a } \\
\text { lot. I want to appreciate myself." }\end{array}$ \\
\hline Participant 2 & $\begin{array}{l}\text { "I've been feeling bad lately. I'm often } \\
\text { gloomy, I'm not feeling well. I'm often } \\
\text { overthinking. I'm too lazy to meet other } \\
\text { people, I also don't have an appetite. I } \\
\text { don't know how to express my emotions } \\
\text { about many incidents of domestic } \\
\text { violence that i've been through." }\end{array}$ & $\begin{array}{l}\text { "I feel calmer now. I realized that } \\
\text { my thoughts were irrational so } \\
\text { that I experienced bad emotions, } \\
\text { my overthinking was less than } \\
\text { before. I really like the safe place } \\
\text { technique and breathing } \\
\text { relaxation." }\end{array}$ \\
\hline $\begin{array}{l}\text { Participant } \\
\text { Participant } 3\end{array}$ & $\begin{array}{l}\text { Before Intervention } \\
\text { "I think I'm stressed and anxious. When } \\
\text { an argument occurs, I tend to be silent. } \\
\text { I'm afraid that the bad things I've had } \\
\text { while dating will happen again in the } \\
\text { future. I felt that no one would accept me } \\
\text { and that I am worthless." }\end{array}$ & $\begin{array}{l}\text { After Intervention } \\
\text { "I like the A-B-C technique } \\
\text { because it allows me to identify my } \\
\text { wrong thoughts. I was also } \\
\text { impressed by the relaxation } \\
\text { techniques taught. I feel more } \\
\text { relaxed. I deserve to be treated } \\
\text { better." }\end{array}$ \\
\hline Participant 5 & $\begin{array}{l}\text { "Ever since I experienced dating violence, } \\
\text { I feel like I'm too irritable. I often } \\
\text { experience negative feelings. I also think } \\
\text { that all men are bad. I was afraid that I } \\
\text { would also be a violent abuser for my } \\
\text { partner. Because i am quite possessive } \\
\text { with my partner" }\end{array}$ & $\begin{array}{l}\text { "There are changes that I } \\
\text { experienced after joining this } \\
\text { program. I became more realistic. I } \\
\text { am able to analyze my irrational } \\
\text { thoughts. I'm not controlled by } \\
\text { bad thoughts anymore so I'm } \\
\text { more comfortable." }\end{array}$ \\
\hline Participant 6 & $\begin{array}{l}\text { "I always have bad thoughts about almost } \\
\text { everything. I choose to lock myself in my } \\
\text { room, not interact with other people, } \\
\text { and increase my sleep time when I } \\
\text { remember the violence that my partner } \\
\text { committed. I think my life is worthless, } \\
\text { there is no purpose in life that I want to } \\
\text { achieve in the future." }\end{array}$ & $\begin{array}{l}\text { "I am more comfortable with } \\
\text { butterfly hugs than relaxation. } \\
\text { Relaxation makes it difficult for me } \\
\text { to focus, dizzy, and nauseous. } \\
\text { Butterfly hugs made me realize I } \\
\text { need to love myself. I no longer } \\
\text { predict the future, I focus on } \\
\text { designing my future life goals. I also } \\
\text { learn a lot from my friends in this } \\
\text { group, I learn how they solve } \\
\text { problems." }\end{array}$ \\
\hline
\end{tabular}


The material and skills (cognitive identification, relaxation, butterfly hugs, safe place, and daily schedule) conveyed through the intervention sessions were evaluated positively and beneficial by the participants. Facilitators, observers, and time management activities online also received positive responses. Furthermore, participants also appreciated the group setting, as fellow participants provide mutual support to each other. However, participant 3 specifically requested an individual session after the group program.

"I like the A-B-C technique because it allows me to identify my wrong thoughts. I was also impressed by the relaxation techniques taught.." (Participant 3)

“... Butterfly hugs made me realize I need to love myself. ..." (Participant 6)

\section{Discussion}

The results of this study indicate the effectiveness of group interventions conducted on 5 young adults who have experienced dating violence. This assessment is based on quantitative non-parametric analysis at pretest, posttest, and follow up (I month after the intervention). The DASS and BDI-II scores decreased both in terms of stress, anxiety, and depression experienced by participants in this study. Therefore, it can be concluded that group intervention is effective in reducing psychological distress in survivors of dating violence. The effectiveness of this intervention group is supported by the results of previous research which examined the effectiveness of the group intervention program that lasted for 8 weeks on 23 women survivors of domestic violence. The results of group intervention in the study found that there was a positive impact shown by the participants. This is indicated by a decrease in victimization and a decrease in the level of depression. Another thing also mentioned is an increase in self-esteem and social support they get (Santos et al., 2017).

The model of group therapy for handling intimate partner violence, including dating violence, is inseparable from the basic need for security, connectedness with one another in group therapy (Lieberman, 2013). Group therapy as a system becomes a protective factor for survivors. With this method, they can rebuild a sense of security and security that has been lost so far. Lieberman (20I3) further explained that group therapy provides a basic human neurobiological need, namely 
connectedness, like that found in family, community, or even nationality. Humans have a primary instinct to have emotional attachment or social connection with those closest to them. Group therapy is a natural modality for rebuilding these instincts, because violence destroys the connectedness with others (Lothstein, 2013). This is also supported by research by Flores (2010) which suggested that in the process of group psychotherapy there is a neurobiological process, where interpersonal interactions build to attachment which will help individuals recover from interpersonal problems they face.

A similar study was also conducted by Schroeder et al. (2018) by analyzing the qualitative content of therapeutic factors in group psychotherapy called Equine-facilitated group psychotherapy for 9 women. This group therapy showed the results of instilling hope, self-understanding, learning from interpersonal interactions, and acceptance. These themes often appear in group members' narratives about the most important and most memorable sessions for them. Group psychotherapy is also performed on survivors of interpersonal trauma (Karatzias et al., 2015). The aim of group psychotherapy is to assist group members in developing skills for their trauma recovery. This group psychotherapy is known as the Trauma Recovery and Empowerment Model (TREM). The group consisted of $7 \mathrm{I}$ consecutive women from the five National Health Services (NHS) in Scotland. The results showed an improvement or reduction in dissociative symptoms and an increase in their selfesteem. At post-treatment and follow-up there was an increase of $54.9 \%$ and $62 \%$ in the results of clinical measures of members of the psychotherapy group.

The superiority of the group intervention model lies in several therapeutic factors that occur in the group intervention process which are its advantages, such as universality, group cohesiveness, interpersonal learning, social microcosm, and 'here and now'. Yalom (in Pomerantz, 20I4) described universality as a phenomenon where group members realise that other members have the same feelings and root causes as themselves. This will help create a homogeneous group. This also happened to the participants during the intervention. For example, in participant 3 and participant 6 , that 'she is not alone with her unpleasant experiences so far, it turns out that many other people have also experienced them. She feels that she gets psychological support, feels more comfortable 


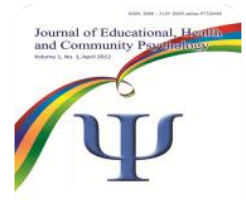

and at ease with herself after sharing experiences and listening to experiences from other group members.

The dimensions of events that give rise to distress are usually viewed as negative events. These negative events can be further perceived as uncontrollable events, ambiguous events, and overload. An uncontrollable event is a situation when a person feels unable to predict, modify and end an unpleasant situation (Taylor, 2006). In this context, the participants experienced dating violence as a negative event beyond their control. This unpleasant incident then gives rise to psychological distress which can include stress, anxiety, and depression. Almost all participants of the current study scored high on all three manifestations of psychological distress (Figure 3) which then decreased after undergoing 7 intervention sessions. Changes in the psychological condition of participants can be seen in the following statements: "I'm often overthinking. I'm too lazy to meet other people, I also don't have an appetite." (Participant 2 on session I) and "I realised that my thoughts were irrational so that I experienced bad emotions, my overthinking was less than before.” (Participant 2 on session 7). The psychological changes were also observed in participant 3, following statements: "I think I'm stressed and anxious..." (on session I) and "... I feel more relaxed..." (on session 7).

The participants reported that they have learned some simple skills via this intervention. These skills include breathing relaxation, techniques to change cognitive distortions (A-B-C method), butterfly hugs, safe place, and I-message. They consider these skills valuable as it helps them deal with the negative events they have experienced and help them in their current struggle to fight the negative impacts of those experiences. Based on the results described, it can be concluded that the group intervention indeed was based on the CBT approach as well as the therapeutic techniques presented by Yalom. The combination of Yalom's theory of group intervention and cognitive-behavioral techniques in this study is suitable for helping young adults to reduce the psychological distress they experience because of violent dating relationships.

\section{Conclusion}

Group intervention is effective in reducing psychological distress in young adults who have experienced intimate partner violence. This is indicated by the significant difference scores on the 


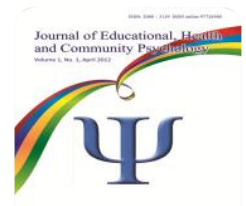

pre-test, post-test, and follow-up (I month after giving the intervention). Furthermore, the material and skills (cognitive identification, relaxation, butterfly hugs, safe place, daily schedule, and pro-cons) included in the protocol were evaluated positively and beneficial by the participants.

\section{Theoretical Suggestions}

The present study recruited 7 participants and only 5 finished all tests and was used in the analysis. A small sample size may compromise statistical power and therefore the significance testing may be biased. Therefore, we suggest a need for further research with more participants to accommodate statistical power and accuracy. A randomised controlled trial (RCT) designed to explore the efficacy and effectiveness of the CBT group therapy intervention protocol for treating psychological distress in young women who are survivors of dating violence by comparing it with other established and evidence-based treatment groups may provide further insights.

\section{Practical Suggestions}

Based on the evidence of the present study, the "Moving Forward: Online group intervention for survivors of dating violence" protocol based on CBT helps treat psychological distress of young women who are survivors of dating violence. We hope that this protocol may provide practitioners with guidelines in treating young women within the same context and scope. It is worth mentioning, however, that we suggest group therapy to be conducted in a small group of 5 to 7 people. Future research may be required to explore the effectiveness of group therapy in a larger group size.

\section{Acknowledgement}

This research was funded by the Faculty of Education (S P DIPA.023.17.2.677507/2020), Universitas Negeri Semarang.

\section{Conflict of Interest}

The authors declare no conflict of interest. 


\section{References}

Adams, E. N., Clark, H. M., Galano, M. M., Stein, S. F., Grogan-Kaylor, A., Graham-Bermann, S. (202I). Predictors of housing instability in women who have experienced intimate partner violence. Journal of Interpersonal Violence, 36(7), 3459-348 I. https://doi.org/ I 0. I I77/08862605 I877700 I

Banyard, V. L., \& Cross, C. (2008). Consequences of teen dating violence: understanding intervening variables in ecological context. Violence Against Women, 14(9), 998-1013. https://doi.org/10.1 I77// 07780I 208322058

Brabender, V. A., Fallon, A. E., \& Smolar, A. I. (2004). Essentials of group therapy. John Wiley \& Sons, Inc.

Carbone-Lopez, K., Kruttschnitt, C., \& Macmillan, R. (2006). Patterns of intimate partner violence and their associations with physical health, psychological distress, and substance use. Public Health Reports, I 2 I (4), 382- 392. https://doi.org/I0. I I77/0033354906 I 210040

Cohen, J. (1992). A power primer. Psychological Bulletin, I/ 2, I55-159. https://doi.org/ I0.1037/

Ezhumalai, S., Muralidhar, D., Dhanasekarapandian, R., \& Nikketha, B. S. (2018). Group interventions. Indian Journal of Psychiatry, 60(4), 5I4-52I.

Field, A. P. (2005). Kendall's coefficient of concordance. In B. S. Everitt \& D. C. Howell, Encyclopedia of Statistics in Behavioral Science Volume 2 (pp. I0I0-I0II). John Wiley \& Sons.

Field, A., Miles, J., \& Field, Z. (20I2). Discovering statistics using R. Sage.

Flores, P. J. (2010). Group psychotherapy and neuro-plasticity: an attachment theory perspective. International Journal of Group Psychotherapy, 60(4), 546-570. https://doi.org/I0.152 I/ijgp.20I0.60.4.546

Forsyth, D. R. (2019). Group dynamics (7th ed.). Cengage Learning.

Gidron, Y. (20I3). Group therapy/intervention. In M. D. Gellman \& J. R. Turner (Eds.), Encyclopedia of Behavioral Medicine (pp. 880). Springer.

Ginting, H. Naring, G, van der Veld, W. M., Srisayekti, W., \& Becker, E. S. (2013). Validating the beck depression inventory-II in Indonesia's general population and coronary heart disease patients. International Journal of Clinical and Health Psychology, 13(3), 235-242. https://doi.org/I0.1016/SI697-2600(I3)70028-0

Grace, S., Pratiwi, P. C., \& Indrawati, G. (2018). The correlation between trust and dating violence among young adults women in Jakarta. Jurnal Psikologi Ulayat: Indonesian Journal of Indigenous Psychology, 5(2), 169-186. https://doi.org//0.24854/jpu78

Gravetter, F. J., \& Forzano, L. B. (20I I). Research methods for the behavioral sciences (4th ed). Cengage Learning.

Haselschwerdt, M. L., Carlson, C. E., \& Hlavaty, K. (202I). The romantic relationship experiences of young adult women exposed to domestic violence. Journal of Interpersonal Violence, 36(7), 30653092. https://doi.org/10.1177/08862605/877/679

James, R. K. (2008). Crisis intervention strategies. Thomson Higher Education. 
Johnson, D. M., Zlotnick, C., \& Perez, S. (20I I). Cognitive-behavioral treatment of PTSD in residents of battered women shelters: Results of a randomized clinical trial. Journal of Consulting and Clinical Psychology, 79(4), 54I-55I. https://doi.org/10.1037/a0023822

Karatzias, T., Ferguson, S., Gullone, A., \& Cosgrove, K. (2015). Group psychotherapy for female adult survivors of interpersonal psychological trauma: A preliminary study in Scotland. Journal of Mental Health, 25(6), 512-519. https://doi.org/I0.3109/09638237.2

Kerlinger, F. N., \& Lee, H. B. (2000). Foundation of behavioral research (4th ed.). Harcourt Inc.

Kim, S., \& Kim, J. (200I). The effects of group intervention for battered women in Korea. Archives of Psychiatric Nursing, I 5(6), 257-264. https://doi.org/ I0.1053/apnu.200I.28682

Lieberman, M. (2013). Social: Why are brains are wired to connect. Crown.

Lothstein, L. M. (20I3). Group therapy with intimate partner violence (IPV). International Journal of Group Psychotherapy 63(3), 499-452. https://doi.org/I0.I52I/ijgp.2013.63.3.449

Luzanil, S. T., \& Menaldi, A. (in press). Efektivitas terapi kelompok kognitif perilaku untuk menangani kecemasan akademik pada mahasiswa rantau. Jurnal Psikologi Ulayat.

Oei, T. P. S., Sawang, S., Goj, Y. W., \& Mukhtar, F. (20I3). Using the depression, anxiety stress scale 21 (DASS-2I) across cultures. International journal of psychology: Journal international de psychologie, 48(6), I0I8-1029. https://doi.org/10.1080/00207594.20I2.755535

Papalia, D. E., \& Martorell, G. (20I4). Experience human development (13th ed.). McGraw-Hill Education.

Pomerantz, A. M. (20I4). Clinical psychology: Science, practice, and culture. Sage Publications, Inc.

Pratiwi, P. C. (20I7). Upaya peningkatan self-esteem pada dewasa muda penyitas kekerasan dalam pacaran dengan cognitive behavior therapy. Jurnal Psikologi Ulayat, 4(2), I4I-I59. https://doi.org/I0.24854/jpu60

Pratiwi, P. C., \& Yasa, S. P. K. (202I). Psychology distress reviewd from young adults who experience dating violence. JournalNX-A Multidiciplinary Peer Reviewed Journal, 7(4), 25-33. https://repo.journalnx.com/index.php/nx/article/view/2828

Santos, A., Matos, M., \& Machado, A. (2017). Effectiveness if a group intervention program for female victims of intimate partner violence. Small Group Research, 48(I), 34-6I. https://doi.org/10.1 I77//10464964/6675226

Schroeder, K., Stroud, D., Sherwood, D. M., \& Udell M.A.R. (2018). Therapeutic factors in equinefacilitated group psychotherapy for women survivors of interpersonal violence. The Journal for Specialists in Group Work, 43(4), 326-348. https://doi.org/I0.1080/01933922.20I8.15I6707

Sullivan, A. M., \& Rivera, E. A. (2013). Counseling services for domestic violence survivor: $A$ review of the empirical evidence. https://www.dvevidenceproject.org/wpcontent/uploads/

Taquette, S. R., \& Monteiro, D. L. M. (2019). Causes and consequences of adolescent dating violence: a systematic review. Journal of injury \& violence research, II(2), I37-I47. https://doi.org/ I0.5249/jivr.v I Ii2.106 I

Taylor, S. E. (2006). Health psychology (6th ed.). McGraw-Hill Education. 


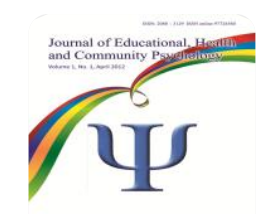

Viejo C., Monks C. P., Sánchez V., \& Ortega-Ruiz R. (2016). Physical dating violence in Spain and the United Kingdom and the importance of relationship quality. Journal of interpersonal violence, 3/(8): | 453-| 475. https://doi.org/ | 0. I |77/08862605 |4567963

Widyana, R., Sumiharso, \& Safitri, R. M. (2020). Psychometric properties of internet-administrated version of depression, anxiety and stress scales (DASS-42) in sample Indonesian adult [Special Issue]. Journal of Talent Development and Excellence, I2(2s) https://iratde.com/index.php/jtde/article/view/536 